"The particular advantage which attaches to this latest modification of the now somewhat discountenanced International Exhibition is, that it brings together apparatus and models which the most attractive World Fair would never have drawn from their retirement. Men of science and students, as a class, are not influenced by the inducements which are most operative with ordinary exhibitors; but none the less is it necessary for the advancement of knowledge that their treasures should be, from time to time, examined and criticised by their fellows.

"There is much of interest in the geological and geographical sections, though nothing very new. Of the metallurgical division-with a miserable dozen exhibits out of a total of nigh on five thousand-what can be said? Is metallurgy devoid of scientific interest? Or has one of the greatest of England's industries no followers who care to do anything for its advancement? With this sole exception, the Science and Art Department must be held to have scored a great success, and to have saved the Government from the reproach of doing nothing for science. It only remains to hope that the magnificent collection which now fills the exhibition galleries will not be dispersed without an effort being made to secure for the nation such portion of it as may be obtainable, and suitable to form the nucleus of a technical and scientific museum, on the plan of the Conservatoire des Arts et Métiers of Paris and the similar institutions to be found in every large German city."

Such is what may be called "lay" opinion upon the importance and success of this unprecedented Collection; and that this opinion is endorsed by that of men of science themselves may be seen from the addresses of Mr. Spottiswoode and Dr. Siemens, which we are able to publish to-day.

\section{THE REMINGTON TYPE-WRITING MACHINE}

I making comparison between the physical and the 1 biological sciences, it is not difficult to recognise how it comes that they differ in one essential element. In the physical the forces in action are comparatively few, and of very different degrees of intensity. The centripetal and centrifugal tendencies, for instance, of moons and planets so far exceed the mutual attractions of the planets inter sese, that in the rough calculations of their orbits the latter may be onitted from consideration.

In the study of the phenomena of life, however, the innumerable forces which are found to be in play are so fairly balanced in their magnitude and tendencies, that the task of dissociating and classifying them is almost beyond the means at the disposal of the human mind.

In the study of the various machines which have from time to time been constructed with the purpose of economising or superseding the employment of the engine - muscle, expensive in the nature of the fuel it requires, although it is so economical in the way in which it uses it, a similar division may be made. In the steam-engine, however developed, the waste of force essential to the working of the valves is nothing in comparison to the power employed, nor in the telegraphic needle is much done by the current except the actual record which it makes.

But on looking at the sewing-machine or the more novel type-printing apparatus we can see that the ingenuity of America, stimulated by the idea of practical advantage, has been developed in a direction, not towards the discovery of more economic principles, but to the employment of forces already known in the mastery of complicated operations previously thought to be beyond the powers of any other mechanism than the hand of man. To obtain these results an entirely different conception has to be introduced. The power at the disposal of the operator has not to be directed simply to the performance of a single operation, like the movement of the needle in the sewing-machine or the impressing of the letter in the type-writer, but has to be distributed so that it may perform a series of simultaneous operations, all leading to a complicated result. The treadle of the sewingmachine in its movement, besides the rise and fall of the needle which it produces, works the thread loop-slip, shifts the fabric, and unwinds the cotton. The pressure on any one of the keys of the type-writer, besides the impression which it stamps upon the paper, shifts that paper, inks the type, and places each letter in its proper sequence.

In order properly to balance all these varied actions, great ingenuity and much practical experiment are necessary, and of the "Remington Type Writer," the only satisfactory instrument of the kind yet brought to public notice, the introducers, the most prominent of whom is Mr. Jefferson M. Clough, superintendent of the Remington Armoury, tells us that "during the time required to perfect the invention, about fifty machines were constructed, all upon the same general principle, but each differing more or less in the minor details."

This general principle is a most ingenious one. It is evicient that the great difficulty in the construction of such an instrument is that it is necessary to have a large number of signs-letters of the alphabet, figures, stops, \&c., arranged in such a manner that any one of them may, by the simple pressure on a corresponding key-note, be printed in any required order or sequence upon a paper sheet placed ready to receive it. There are many more or less elaborate ways in which this may be accomplished; none, we believe, so simple as that adopted by the Messrs. Remington. Their apparatus may be compared to a piano, even in its details. There is a key-board, on each key of which the letter it impresses is to be found indicated. The depression of each key raises a hammer. This hammer, however, instead of being covered with a felted pad, as in the piano, carries at its extremity a typecast letter, which, in place of a stretched wire, strikes on a piece of paper the impression of the letter which it bears. So far the similarity between the two instruments is very close. But to produce sounds and to perpetuate impressions in black and white in any definite sequence, are two very different things, the latter being much the more difficult; and herein lies the ingenuity of the principle adopted in the typewriter. The hammers, instead of being arranged in one line, as in the piano, form a circle, in the exact centre of which each type-letter at the end of its hammer-lever strikes upwards. Two keys struck at the same time must consequently cause two type-letters to clash in their attempt to reach the same spot, the centre of the circle. This, however, does no injury to the instrument, although care must be taken not to cause it. Above the circle of levers the recording paper is situated, rolling on a drum, towards the operator, the whole being so placed that just before any letter of a word is struck that part of the 
paper on which the letter has to be impressed is rearly over the middle of the lever-circle. The depression of the key first moves the paper into the exact position and then prints the letter, figure, or stop. An independent key produces the blank between each two words.

The method of inking is excellent and unexpected. A strip of fine fabric, saturated with the ink is carried between two rollers so arranged that it intervenes between the paper to be printed on and the centre of the levercircle. The type-carrying hammers do not, therefore, strike the paper itself at all, but only the ink-saturated band, which, as a result of the percussion, comes in contact with the recording paper, but only in the parts where contast is made, which are nothing more nor less than those corresponding to the configuration of the letter or figure employed. There is a simple shifting apparatus to carry this inking band from one roller to the other, and afterwards back again, which prevents the same part from being struck too often.

A side lever shifts the paper at the end of each line, and a small bell is struck to warn the operator when this has to be employed.

Into further detail we need scarcely enter. The whole instrument is not larger than a sewing-machine. Its cost is twenty guineas. It only writes in capitals, the total number of keys being forty-four, arranged in four rows of eleven in each. Its simplicity is the best guarantee of its durability.

As to the "typoscript" (in contradistinction to the manuscript of ordinary handwriting), there is no comparison between its clearness and that of average penmanship. It has, in fact, all the appearances of print, with its many advantages as regards legibility, compactness, and neatness. Errors, if detected soon enough, can be corrected by the repetition of the word or sentence, and the subsequent obliteration, upon reperusal, of the faulty lines. The ink employed can be transferred like transfer ink.

The principal question which this beautiful and ingenious little instrument suggests to our minds is, whether it would not be better for every one of us to learn the Morse telegraph language, and employ it for writing upon all occasions instead of the cumbrous letters now in vogue. Thought is more quick than formerly. Germany is rapidly rejecting its archaic type; why should we not go further and write in Morse, where spots and horizontal lines do duty for all necessary signs, and type-writers of the simplest form would be required?

\section{ORIGIN OF LIFE}

On Fermentation. By P. Schützenberger, Director at the Chemical Laboratory at the Sorbonne. With twentyeight Illustrations. (Henry S. King and Co., 1876. )

Sur la Génération des Ferments. Par E. Fremy, Membre de l'Academie des Sciences, Professeur de Chimie à l'Ecole Polytechnique et au Muséum d'Histoire Naturelle. (G. Masson, Editeur, Libraire de. l'Aca( émie de Médecine: 1875.)

Evolution and the Origin of Life. By $\mathrm{H}$. Charlton Bastian, M.A., M.D., F.R.S., Professor of Pathological Anatomy in University College, London. (London: Macmillan and Co., 1874 .)

7 HE work on fermentation is one of the International Scientific Series. Starting with a thoroughly philosophical conception of his subject, the author points out that from our present stand-point of knowledge, all those phenomena classed together under the name fermentation, are but special cases of the chemical phenomena of life. To life, however, we are not to attribute any extra-material force or influence. Though the force that can reduce the complex chemical edifice called sugar in a certain determinate direction, is manifested only in the living cell of the ferment, yet this "is a force as material as all those we are accustomed to utilize." "In other words, there is really no chemical vital force. If living cells produce reactions which seem peculiar to themselves, it is because they realise conditions of molecular mechanism which we have not hitherto succeeded in tracing, but which we shall, without doubt, be able to discover at some future time." In the book will be found a clear and concise statement of our present knowledge of fermentation, and a brief history of the progress of opinion and research. The outstanding questions (and there are many) and diverse opinions are presented with scientific impartiality, as is also contradictory evidence. It is gratifying to observe how such rival theories as those of Liebig and Pasteur on the nature of fermentation can be swallowed up in a larger conception, and one at least of the combatants conclude that both may be right. "Fermentation," says Liebig, "is a movement communicated by instable bodies in process of chemical transformation." "I maintain," says M. Pasteur, "that the chemical act of fermentation is essentially a phenomenon correlative to a vital act." "So be it," replies Liebig, " a vital act' is a phenomenon of motion; your special views fall within my theory." Necessarily large space in this work is given to the extensive and splendid researches of $M$. Pasteur, whose views the author follows in the main, though not at all times able to find them quite self-consistent or consistent with admitted facts. On the great question of most general interest-What is the origin of ferments? he adopts the conclusions of M. Pasteur.

The origin or generation of ferments is the subject of the work by M. Fremy, who has long and ably contested the theory maintained by $M$. Pasteur. According to this last distinguished chemist, all ferments are the offspring of living things similar to themselves; and when these organisms appear in any liquid, such as milk, or the juice of the grape, it is because the germs or eggs of these creatures have in some way been introduced into the liquid. M. Pasteur has made a great many interesting and most important experiments which to his mind demonstrate the doctrine of panspermism. The demonstration, however, is not universally accepted; and M. Fremy is among those who find it possible to admit the accuracy of most, if not of all, M. Pasteur's experiments without accepting his conclusions, while they in their turn bring forward observations and experiments which they hold to be quite irreconcilable with the hypothesis that ferments are always produced from germs of similar organisms. We can in no way refer to the innumerable experiments ; we may, however, try to give in a few words some faint conception of the character of the discussion.;

Whence, for instance, come the well-known organisms which appear in the expressed juice of the grape, and are invariably associated with alcoholic fermentation? "From germs that have found access to the liquid," says M. Pasteur. "No," replies M. Fremy, "they are evolved, 